I Oct. I974 to I Oct. I975. The effects of crossbreeding were studied in single crosses, backcrosses, alternate back-crosses and in unsystematized crosses, regarding the numbers of piglets born, the numbers born alive, and the numbers surviving at an age of 2-6 weeks. For piglets born alive in the above-named crossbreeding types, the effects were $0.27,0.47,0.34$ and 0.20 respectively. The corresponding figures for survivors at an age of $2-6$ weeks were $0.33,0.55,0.42$ and 0.29 .

\author{
TESTIS GROWTH IN "POLISH MERINO" AND “ ILE-DE-FRANCE" RAMS \\ AND I'TS REI,ATIONSHIP WITH PROLIFICACY OF EWES \\ M. J. RADOMSKA, J. KLEWIEC and F. MAJZNER \\ Institute of Biological Bases of Animal Breeding \\ Agricultural University, ul. Rakowiecka 26/30, o2-528 Warsaw, Poland
}

Experiments were conducted in 1977 in the same state farm on 97 Polish Merino rams (49 single-borns and 48 twins) and 70 Ile-de-France rams (26 singles and 44 twins). Measurements of the testis diameter were carried out after Land's (I975) method at the ages of 6, Io and I4 weeks.

The correlation coefficients between body weight and the diameters of testes were: in Polish Merino $r=0,348$, in Ile-de-France $r=0,554$. Differences in dimensions of testes were significant as the effect of the parental birth-type.

\title{
SIDE EFFECTS OF SELECTION FOR BODY WEIGH IN LABORATORY MICE
}

\author{
Elzbieta MICHALSK $\check{A}$ \\ Institute of Biological Bases of Animal Breeding \\ Agricultural University, ul. Rakowiecka 26/3o, \\ 02-528 Warsaw, Poland
}

Observations were made on the growth and developmient of mouse lines obtained in long term selection for body weight on the 2 ist day of life, a control line and reciprocal crossbreds of all combinations of these lines. Individual body weights were recorded on days I, I2, 2 I, 42, 57 and 72 after birth. Approximate feed uptake and age at which the following developmental traits appeared were also recorded: appearance of external ears, opening of eyes, appearance of hair coat, nipples and opening of vagina.

It was found that long term selection for body weight on 2 ist day differentiated the growth ability of young individuals. The differences appeared only after weaning in the high weight mice in the form of compensatory growth. The effects of heterosis, as regards body weight in crossbreds, are slight and appear mainly in the perweaning period, this beeing seemingly connected with the mother's performance. Comparison of reciprocal crossbreds shows a superiority of the mother's performance of females of the control line over that low weight line and a smaller superiority of females of the high weight over those of low weight line and a lack of significant differences in mothers' performance between the high and low weight lines. Analysis of some developmental traits indicated a retardation in the development of the young from the low weight line and no response of the heavy weight line. The influence of the paternal and maternal lines was revealed as regards earlier time of eyes opening (prevalence of paternal line $C$ vs $L$, maternal line $C$ vs $L$ and $O$ ). This also concerned earlier time of sexual maturation of the females (prevalence of paternal line $O$ vs $I, C$ vs $O$ and maternal line $C$ vs $L$ and $O$ ).

\section{IDENTITY COEFFICIENTS AND GENETIC VARIABILITY IN THEORETICAI, GENETICS}

\author{
C. CHEVALET, M. GILLOIS \\ Labovatoive de Génétique cellulaive, \\ Centre de Recherches de Toulouse, I.N.R.A. \\ B.P. I2-3132o Castanet Tolosan, France
}

Definition, significance and computation rules of identity coefficients are reviewed with emphasis on their use in the quantitative genetics models. 